\title{
EFISIENSI JURUSAN DI DALAM PERGURUAN TINGGI DENGAN MENGGUNAKAN DATA ENVELOPMENT ANALYSIS (DEA)
}

\author{
Riska Maulani Ahmi ${ }^{1}$, Nurafni Eltivia ${ }^{2}$, Andi Kusuma Indrawan ${ }^{3}$ \\ Program Studi Akuntansi Manajemen, Politeknik Negeri Malang \\ Jl. Soekarno Hatta No. 09 Malang, Jawa Timur, 65141 \\ Email : ${ }^{1}$ riskaahmi@yahoo.com, ${ }^{2}$ neltivia@gmail.com,${ }^{3}$ indrawan.andi@gmail.com
}

\begin{abstract}
Abstrak
Penelitian ini bertujuan untuk mengetahui tingkat efisiensi jurusan di Politeknik Negeri Malang. Sampel yang digunakan adalah seluruh jurusan yang berada di Politeknik Negeri Malang. Alat analisis data dalam penelitian ini adalah menggunakan Data Envelopment Analysis dengan model CCR asumsi CRS (Constant Rerutn to Scale). Variabel input yang digunakan ialah jumlah Biaya Opersional dan Biaya Personalia, Jumlah Dana Penelitian, Jumlah Tenaga Pendidik dan Kependidikan, dan Jumlah Mahasiswa Aktif. Kemudian untuk Variabel output yang digunakan ialah Jumlah Lulusan dan Jumlah Penelitian. Hasil penelitian ini menunjukan bahwa dari tahun 2014 sampai dengan 2016 tingkat efisiensi jurusan bervariasi, ada yang efisien dan adapula yang inefisien. Pada tahun 2014 dari 7 Jurusan terdapat 6 jurusan yang efisien yakni AK TE, TI, TM, TS, dan TK dan 1 jurusan yang inefisien yakni AN. Pada tahun 2015 dari 7 jurusan, seluruhnya dalam kondisi efisien. kemudian pada tahun 2016 dari 7 jurusan terdapat 4 jurusan yang efisien yakni TE, TI, TK, dan TS dan 3 jurusan yang inefisien yakni AK, AN, dan TM. Simpulan dari penelitian ini ialah bahwa selama 2014 sampai dengan 2016 Jurusan di Polinema belum semuanya memiliki skor efisien.
\end{abstract}

Kata kunci: Efisiensi, Data Envelopment Analysis, Tingkat Efisiensi Jurusan

\begin{abstract}
The aim of this research was to find level determination of department efficiency in State Polytechnic of Malang. The samples were all Departments in the State Polytechnic of Malang. The efficiency level was measured by Data Envelopment Analysis (DEA) with CCR model and CRS assumption (Constant Return to Scale). The input variables used in this research were, operational costs and personnel costs, number of lecturers and staff, number of students, while the output was the number of researches and the number of graduates. The results of this study shows that from 2014 to 2016, it is found that some Departments are efficient while the rest are inefficient. In 2014, 4 of 7 Departments were efficient (namely Accounting Department, Electronical Engineering Department, Information Technology Department, Civil Engineering Department) and the 3 inefficient Departments were (Business Administration Department, Chemmical Engineering Department, Mechanical Engineering Department). In 20155 of 7 Departments were efficient (namely Accounting Department, Electonical Engineering Department, Information Technology Department, Chemmical Engineering Department, and Civil Engineering Department) and 2 Departments were inefficient (Business Administration Department and Mechanical Engineering). Then in 20163 of 7 Departments were efficient (namely there are 3 departments inneficient there are (Information Technology Department, Chemmical Engineering Department, Civil Engineering Department) and 4 departments were inefficient there are (Accounting Department, Business Administration Department, Electronical Engineering Department, and Mechanical Engineering Department). The conclusion of this study is that during the years 2014 to 2016, not all of the Departmens in Polinema have no efficient score.
\end{abstract}

Keywords: Efficiency, Data Envelopment Analysis, Efficiency department

\section{Pendahuluan}

Salah satu tujuan Perguruan Tinggi menurut Undang-undang Republik Indonesia nomor 12 tahun 2013 tentang Pendidikan Tinggi ialah dihasilkannya lulusan yang menguasai cabang Ilmu Pengetahuan dan/atau Teknologi untuk memenuhi kepentingan nasional dan peningkatan daya saing bangsa. Hal tersebut dapat dicapai dengan membangun pendidikan tinggi yang kompetitif dan kualitatif 
dengan lembaga yang mengoperasikan sumber daya yang ada secara efisien.Al-Bagoury (2013) berpendapat bahwa efisiensi membutuhkan perhatian yang khusus karena semakin meningkatnya peminat untuk melanjutkan ke Perguruan Tinggi.

Selama ini dalam Perguruan Tinggi menggunakan akreditasi dari BAN-PT sebagai alat untuk mengevaluasi kinerja mereka. Namun instrumen yang didalamnya belum cukup untuk menganalisis efisiensi Perguruan Tinggi, hal ini diperkuat oleh pendapat Al-Bagoury (2013) bahwa Perguruan Tinggi memiliki banyak input dan output, sehingga dalam hal ini metode yang memungkinkan untuk menentukan efisiensi kinerja Perguruan Tinggi adalah dengan Data Envelopment Analysis (DEA).

Penelitian yang sama pernah dilakukan oleh Eltivia, et al (2015) di Politeknik Negeri Malang. Peneliti masih menggunakan beberapa Program Studi pilihan, tidak semua Program Studi yang ada di Politeknik Negeri Malang menjadi sasaran penelitian. Maka penelitian kali ini merupakan pengembangan dari penelitian sebelumnya yang dilaksanakan oleh Eltivia, et al (2015) dengan menggunakan input dan output yang berbeda yakni jumlah Tenaga Pendidik dan Kependidikan, jumlah Biaya Operasional dan Biaya Personalia, Jumlah Dana Penelitian, dan jumlah Mahasiswa Aktif sebagai input, sedangkan jumlah Lulusan dan jumlah Penelitian sebagai output.

Tujuan penelitian ini ialah untuk melihat tingkat efisiensi Jurusan di Politeknik Negeri Malang dalam kurun waktu tiga tahun yakni selama tahun 2014 sampai dengan 2016.

\section{Perumusan Masalah}

Berdasarkan latar belakang yang telah dijabarkaan sebelumnya, penulis membuat rumusan masalah dari penelitian ini ialah: bagaimana tingkat efisiensi Jurusan di Politeknik Negeri Malang dengan menggunakan metode Data Envelopment Analysis (DEA) periode tahun 2014-2016.

\section{Tujuan}

Adapun tujuan penelitian ini ialah untuk mengetahui tingkat efisiensi Jurusan di Politeknik Negeri Malang dengan metode Data Envelopment Analysis (DEA) periode tahun 2014-2016.

\section{Efisiensi}

\section{Kajian Pustaka}

Efisiensi merupakan parameter kinerja yang melihat kemampuan entitas dalam menghasilkan output yang optimal dengan input yang ada (Abidin, 2009).

Efisiensi adalah bentuk keberhasilan dalam menggunakan sumber daya (input) yang ada untuk menghasilkan output yang optimal. Konsep efisiensi ekonomi Perguruan Tinggi mencakup dua jenis efisiensi, yakni Efisiensi Teknis yang berarti kemampuan lembaga untuk menghasilkan jumlah maksimum produksi menggunakan input yang tersedia dan efisiensi alokatif yang mengacu pada kemampuan institusi untuk menggunakan campuran input yang optimal, dengan mempertimbangkan harga input dan teknik produksi yang tersedia.

\section{Teknik Pengukuran Efisiensi}

Teknik pengukuran efisiensi dapat fokus pada sisi input (input oriented) maupun fokus pada sisi output (output oriented). Pengukuran berorientasi input adalah pengukuran yang menunjukan seumlah input dapat dikurangi secara proporsional tanpa mengubah jumlah output yang dihasilkan, sedangkan pengukuran berorientasi output adalah berapa banyak kuantitas input bisa dikurangi secara proporsional untuk memproduksi kuantitas output yang sama.

Untuk mengukur efisiensi dapat digunakan sebuah metode non parametrik yakni Data Envelopment Analysis (DEA). DEA merupakan teknik pengukuran efisiensi non-parametrik yang menggunakan program linier dalam melihat perbandingan rasio input dan output pada semua unit penelitian atau Decision Making Unit (DMU). Rumus sederhana Efisiensi adalah sebagai berikut:

Efisiensi = output $/$ input

\section{Metode Perhitungan DEA}

Perhitungan DEA pertama kali diperkenalkan oleh Charnes et al (1978) yang kemudian melahirkan sebuah model DEA yakni CCR. Dalam model CCR diperkenalkan mengenai ukuran efisiensi pada setiap DMU yang merupakan rasio maksimum input dan output yang terbobot. Masing-masing nilai terbobot dari input dan output tersebut ditentukan batasannya, bahwa rasio yang sama pada masingmasing DMU harus memilki nilai yang kurang atau sama dengan satu. Sehingga akan mereduksi multiple input dan multiple output kedalam virtual input dan virtual output tanpa membutuhkan nilai bobot. Maka, ukuran efisiensi merupakan sebuah fungsi nilai bobot dari virtual input dan virtual output. Ukuran efisiensi DMU dapat dihitung dengan permasalahan programming matematika sebagai berikut.

$$
\begin{gathered}
\operatorname{Max} Z_{0}=\frac{\sum_{r=1}^{x} v y_{r 0}}{\sum_{i=1}^{s} u_{i} x_{i 0}} . \quad \text { Subject to } \\
\frac{\sum_{r=1}^{s} v_{r} y_{r^{\prime}}}{\sum_{r=1}^{s} u_{i} x_{i j}} \leq 1, \mathrm{j}=1,2,3, \ldots, \mathrm{n} \\
u_{r} \geq 0, r=1,2, \ldots, s ; v_{i} \geq 0, i=1,2, \ldots, m .
\end{gathered}
$$


Xij adalah nilai input yang diamati dengan tipe ke-i dari DMU ke-j dan Xij > 0 untuk $\mathrm{I}=$ $1,2,3, \ldots, m$ dan $j=1,2, \ldots, n$. demikian juga dengan Yrj adalah nilai output yang diamati dengan tipe ke1 dari DMU ke-j dan Yrj $>0$ untuk $i=1,2, \ldots$, m dan $\mathrm{j}=1,2, \ldots, \mathrm{n}$.

Pada rumus yang digunakan untuk memecahkan permasalahan programming diatas dapat dilihat dari variabel $\mathrm{Ur}$ dan $\mathrm{Vi}$ yang merupakan nilai bobot untuk memecahkan masalah programming. Namun seperti yang terlihat bahwa pemecahan yang ada tidak terbatas. Oleh karena itu dengan mengikuti transformasi Charnes-Cooper, maka solusi yang dapat digunakan ialah sebagai berikut :

$$
\sum u_{i} x_{i 0}=1
$$

Maka didapatkan linier programming model CCR dengan asumsi CRS dapat digunakan rumus sebagai berikut :

$$
\begin{aligned}
& \operatorname{Max} \mathrm{Z}_{0}=\sum_{\text {Subject to }} \sum_{r=1}^{\mathrm{s}} Y_{r 0} \\
& \sum_{\mathrm{r}=1}^{\mathrm{s} Y r j} \quad-\sum_{\mathrm{i}=1}^{\mathrm{m}} U \mathrm{UX} i_{0}=1 . \\
& \operatorname{Vr} \geq 0, \mathrm{r}=1,2, \ldots, \mathrm{s} ; \mathrm{Ui} \geq 0, \mathrm{I}=1,2, \ldots, \mathrm{m} .
\end{aligned}
$$

Sama halnya dengan alat perhitungan lainnya, DEA memiliki kekurangan dan juga kelebihan, menurut Akbar (2009) DEA memiliki kekurangan yakni :

a. Karena DEA merupakan sebuah extream point technique, maka kesalahan-kesalahan pengukuran dapat mengakibatkan masalah yang signifikan.

b. DEA hanya mengukur efisiensi relative dari DMU, dan tidak mengukur efisiensi absolut. Dengan kata lain DEA hanya menunjukkan perbandingan baik buruk apa yang telah dilakukan sebuah DMU dibandingkan dengan sekumpulan DMU sejenis.

c. Karena DEA adalah teknik non parametrik, maka uji hipotesis secara sistematik sulit dilakukan

d. Menggunakan perumusan linier programming terpisah untuk tiap DMU, maka perhitungan secara manual membutuhkan waktu apalagi untuk masalah yang besar, namun hal ini dapat diatasi dengan adanya aplikasi.

Terlepas dari kekurangan yang dimiliki oleh DEA, DEA juga memiliki kelebihan menururt Akbar (2009) yakni :

a. DEA dapat menangani pengukuran efisiensi secara relatif beberapa DMU sejenis yang menggunakan banyak input dan banyak output. b. Dengan metode ini, tidak diperlukan mencari asumsi bentuk fungsi hubungan antara variabel input dan output dari DMU sejenis yang akan diukur efisiensinya.

c. Dalam metode ini, setiap DMU tersebut dibandingkan secara langsung dengan sesamanya.

d. Faktor input dan output dapat memiliki satuan pengukuran yang berbeda.

Biaya menjadi salah satu komponen variabel dalam penelitian ini, biaya selalu muncul jika berhubungan dengan kegiatan produksi.Perguruan Tinggi merupakan sebuah lembaga yang menghasilkan atau memproduksi lulusan terbaik.

Menurut Mulyadi (2008, p8) menyatakan bahwa dalam arti luas biaya adalah pengorbanan sumber ekonomis, yang diukur dalam satuan uang yang telah terjadi atau kemungkinan akan terjadi untuk mencapai tujuan tertentu.Pembiayaan pendidikan menurut PP tahun 2005 pasal 62 terdiri dari :

1. Biaya Investasi satuan pendidikan sebagaimana dimaksud diatas meliputi biaya penyediaan sarana dan prasarana pengembangan sumber daya manusia, dan modal kerja tetap.

2. Biaya Personal meliputi biaya pendidikan yang harus dikeluarkan oleh peserta didik untuk bisa mengikuti proses pembelajaran secara teratur dan berkelanjutan.

3. Biaya Operasional satuan pendidikan sebagaimana dimaksud meliputi telekomuniakasi, pemeliharaan sarana dan prasarana, uang lembur, transportasi, konsumsi, pajak, asuransi, dan lain sebagainya

\section{Penelitian Terdahulu}

Sebelumnya terdapat beberapa penelitian serupa yang telah dilakukan oleh peneliti terdahulu. Seperti yang dilakukan oleh Kao dan Hung (2006) dengan judul penelitian yakni Efficiency Analysis of University Departements : An Empirical Study. Dalam penelitian tersebut digunakan input berupa Jumlah Tenaga Personalia, Biaya Operasional dan Jumlah Ruangan, sedangkan output yang digunakan adalah total jam kuliah, dan jumlah publikasi. Dari penelitian tersebutdiperoleh hasil bahwa Jurusan Kesehatan dalam universitas yang diteliti menggunakan sumber daya relatif besar terhadap output yang dihasilkan.

Eltivia, Setiawan, dan Ernawati (2015) juga melakukan penelitian serupa di Politeknik Negeri Malang dengan judul yakni Study Program's Evaluation Using Data Envelopment Anlysis. Dalam penelitian tersebut digunakan input berupa Jumlah Siswa, Jumlah Dosen, dan Total Anggaran, sedangkan output yang digunakan yakni Jumlah Penelitian dan Jumlah Mahasiswa Lulus.

Jati Handaru (2015) dalam penelitiannya yang berjudul Penilaian Efisiensi Universitas LPTK di Indonesia dengan Menggunakan Data Envelopment 
Analysis. Menggunakan input berupa Jumlah Dosen dan Jumlah Mahasiswa Aktif, sedangkan untuk outputnya berupa Produktifias Pembelajaran, Jumlah rogram Studi dengan Akreditasi A.

\section{Metode Penelitian}

Penelitian ini menggunakan jenis penelitian kuantitatif dengan metode non parametrik Data Envelopment Analysis (DEA) yang bertujuan untuk melihat tingkat efisiensi Program Studi yang berada di Politeknik Negeri Malang dengan membandingkan antara variabel inputdan variabel output. Variabel input $(\mathrm{X})$ dalam penelitian ini adalah Biaya Operasional dan Biaya Personalia, Dana Penelitian, Tenaga Pendidik dan Kependidikan, dan Jumlah Mahasiswa Aktif. Sedangkan Variabel Output (Y) dalam penelitian ini adalah Jumlah Lulusan dan Jumlah Penelitian.

Sumber data yang digunakan dalam penelitian ini ialah data primer yakni Laporan Keuangan, data JumlahTenaga Pendidik dan Kependidikan, data Mahasiswa Aktif dan Mahasiswa Lulus, serta data Jumlah Penelitian pada tahun 2014 hingga 2016 masing-masing jurusan yang telah dipilih sebagai sampel. Terdapat empat variabel input dan dua variabel output yang dapat dilihat dalam tabel 1 dan tabel 2 berikut ini.

Tabel 1

Spesifikasi Input

\begin{tabular}{|l|l|l|}
\hline Variabel input & \multicolumn{1}{|c|}{ Definisi } & \multicolumn{1}{|c|}{$\begin{array}{c}\text { Sumber } \\
\text { Data }\end{array}$} \\
\hline $\begin{array}{l}\text { Biaya } \\
\text { Personalia dan } \\
\text { Biaya } \\
\text { Operasional }\end{array}$ & $\begin{array}{l}\text { Sejumlah dana } \\
\text { yang } \\
\text { dikeluarkan } \\
\text { dalam proses } \\
\text { pendidikan }\end{array}$ & $\begin{array}{l}\text { Bagian } \\
\text { Keuangan }\end{array}$ \\
\hline $\begin{array}{l}\text { Dana } \\
\text { Penelitian }\end{array}$ & $\begin{array}{l}\text { Sejumlah dana } \\
\text { yang } \\
\text { dikeluarkan }\end{array}$ & $\begin{array}{l}\text { Penelitian } \\
\text { dan } \\
\text { Pengabdian }\end{array}$ \\
\hline
\end{tabular}

4. Jurusan Teknik Kimia

5. Jurusan Akuntansi

6. Jurusan Administrasi Niaga

7. Jurusan Teknologi Informasi

Berikut data yang diperoleh :

\begin{tabular}{|l|l|l|}
\hline & $\begin{array}{l}\text { untuk } \\
\text { melakukan } \\
\text { penelitian }\end{array}$ & $\begin{array}{l}\text { Masyarakat } \\
\text { (P2M) }\end{array}$ \\
\hline $\begin{array}{l}\text { Jumlah } \\
\text { Aktif }\end{array}$ & $\begin{array}{l}\text { Jumlah } \\
\text { mahasiswa } \\
\text { aktif berkuliah } \\
\text { pada tahun } \\
\text { yang } \\
\text { bersangkutan }\end{array}$ & $\begin{array}{l}\text { Bagian } \\
\text { Pusat } \\
\text { Sistem } \\
\text { Informasi } \\
\text { (PSI) }\end{array}$ \\
\hline $\begin{array}{l}\text { Jumlah Tenaga } \\
\text { Pendidik dan }\end{array}$ & $\begin{array}{l}\text { Jumlah } \\
\text { pengajar pada } \\
\text { tahun yang } \\
\text { bersangkutan }\end{array}$ & $\begin{array}{l}\text { Bagian } \\
\text { Pusat } \\
\text { Sistem } \\
\text { Informasi } \\
\text { (PSI) }\end{array}$ \\
\hline
\end{tabular}

Tabel 2

Spesifikasi Output

\begin{tabular}{|l|l|l|}
\hline \multicolumn{1}{|c|}{$\begin{array}{c}\text { Variabel } \\
\text { output }\end{array}$} & \multicolumn{1}{|c|}{ Definisi } & \multicolumn{1}{|c|}{$\begin{array}{c}\text { Sumber } \\
\text { Data }\end{array}$} \\
\hline $\begin{array}{l}\text { Jumlah } \\
\text { Lulusan }\end{array}$ & $\begin{array}{l}\text { Jumlah siswa } \\
\text { lulusan }\end{array}$ & $\begin{array}{l}\text { Bagian } \\
\text { Pusat } \\
\end{array}$ \\
& & $\begin{array}{l}\text { Sistem } \\
\text { Informasi } \\
\text { (PSI) }\end{array}$ \\
\hline $\begin{array}{l}\text { Jumlah } \\
\text { Penelitian }\end{array}$ & Jumlah & Bagaian \\
& penelitian & Penelitian \\
& mahasiswa & dan \\
& & Pengabdian \\
& & Masyarakat \\
& & (P2M) \\
\hline
\end{tabular}

Populasi yang digunakan dalam penelitian ini ialah seluruh Jurusan yang ada di Politeknik Negeri Malang. Kemudian di pilih menggunakan sampel jenuh yakni menggunakan seluruh populasi sebagai sampel yang terdiiri dari:

1. Jurusan Teknik Elektri

2. Jurusan Teknik Mesin

3. Jurusan Teknik Sipil

Tabel 3

Data Variabel Input dan Output 2014-2016

\begin{tabular}{|c|c|c|c|c|c|c|c|}
\hline \multirow[b]{2}{*}{ Tahun } & \multirow[b]{2}{*}{ Jurusan } & \multicolumn{4}{|c|}{ Input } & \multicolumn{2}{|c|}{ Output } \\
\hline & & $\begin{array}{c}\text { Jumlah Tenaga } \\
\text { Pendidik dan } \\
\text { Kependidikan }\end{array}$ & $\begin{array}{c}\text { Jumlah } \\
\text { Mahasiswa } \\
\text { Aktif } \\
\end{array}$ & $\begin{array}{c}\text { Biaya Operasional } \\
\text { dan Biaya } \\
\text { Personalia } \\
\end{array}$ & $\begin{array}{c}\text { Dana } \\
\text { Penelitian } \\
(000) \\
\end{array}$ & $\begin{array}{l}\text { Jumlah } \\
\text { Lulusan }\end{array}$ & $\begin{array}{c}\text { Jumlah } \\
\text { Penelitian }\end{array}$ \\
\hline \multirow{5}{*}{2014} & $\mathrm{TE}$ & 116 & 1.744 & 11.791 .276 .676 & 108.800 & 412 & 34 \\
\hline & $\mathrm{TM}$ & 88 & 2.692 & 7.701795 .228 & 92.800 & 219 & 29 \\
\hline & $\mathrm{TS}$ & 75 & 453 & 6.439 .790 .991 & 57600 & 144 & 18 \\
\hline & TK & 47 & 378 & 3.083 .628 .191 & 22400 & 95 & 7 \\
\hline & $\mathrm{AK}$ & 61 & 1.179 & 5.273 .101 .712 & 70.400 & 254 & 29 \\
\hline
\end{tabular}

175 | Jurnal Akuntansi, Ekonomi dan Manajemen Bisnis | Vol. 6, No. 2, Dec 2018, 172-178 | E-ISSN: 2548-9836 


\begin{tabular}{|c|c|c|c|c|c|c|c|}
\hline & AN & 55 & 1.079 & 5.072 .602 .931 & 57.600 & 198 & 18 \\
\hline & TI & 35 & 984 & 3.097 .585 .163 & 28800 & 188 & 9 \\
\hline \multirow{7}{*}{2015} & $\mathrm{TE}$ & 106 & 2.009 & 12.041 .249 .161 & 185.800 & 410 & 60 \\
\hline & TM & 76 & 3.068 & 8.507 .663 .371 & 117.100 & 250 & 38 \\
\hline & $\mathrm{TS}$ & 75 & 536 & 6.808 .545 .059 & 105.300 & 200 & 34 \\
\hline & TK & 46 & 449 & 3.315 .870 .791 & 64.250 & 102 & 21 \\
\hline & $\mathrm{AK}$ & 71 & 1.313 & 5.581 .310 .379 & 102.050 & 311 & 33 \\
\hline & AN & 57 & 1.219 & 5.515 .438 .168 & 64650 & 232 & 21 \\
\hline & TI & 48 & 1.200 & 3.060 .230 .837 & 61.800 & 198 & 20 \\
\hline \multirow{7}{*}{2016} & $\mathrm{TE}$ & 102 & 2.268 & 14.545 .962 .527 & 170.800 & 469 & 56 \\
\hline & TM & 75 & 3.486 & 9.710 .094 .015 & 138.650 & 226 & 45 \\
\hline & TS & 68 & 575 & 7.986 .456 .293 & 77.250 & 210 & 25 \\
\hline & TK & 36 & 559 & 3.739 .019 .393 & 73.250 & 115 & 24 \\
\hline & $\mathrm{AK}$ & 67 & 1.456 & 7.151.597.717 & 117.500 & 310 & 38 \\
\hline & AN & 58 & 1.335 & 6.610 .391 .986 & 86.200 & 267 & 28 \\
\hline & TI & 39 & 1.312 & 3.765 .127 .968 & 77.200 & 278 & 25 \\
\hline
\end{tabular}

\section{HASIL DAN PEMBAHASAN}

Setelah data terkumpul maka data kemudian diolah dengan menggunakan aplikasi Banxia Frontier Analys 4.Model yang digunakan ialah CCR dengan asumsi CRS. Asumsi tersebut dapat digambarkan dengan program linier sebagai berikut

$$
\begin{aligned}
& \operatorname{Max} Z_{0}=\sum_{V_{r} Y_{r 0}} \\
& \text { Subject to } \sum_{\mathrm{r}=1}^{\mathrm{s}} \operatorname{VrYrj} \quad-\sum_{\mathrm{i}=1}^{\mathrm{m}} \text { UrYrj } \\
& \sum_{\mathrm{r}=1}^{\mathrm{s}} \operatorname{UiXi}_{0}=1 .
\end{aligned}
$$

$\mathrm{Vr} \geq 0, \mathrm{r}=1,2, \ldots, \mathrm{s} ; \mathrm{Ui} \geq 0, \mathrm{I}=1,2, \ldots, \mathrm{m}$

Dimana :

$\mathrm{Z}_{0}=$ Efisiensi dari decision

making unit (DMU)

$\mathrm{Ui}=$ Bobot input $\mathrm{i}$

$\mathrm{Vr}=$ Bobot output $\mathrm{r}$

Yrj = Jumlah output $r$ yang dihasilkan oleh DMU ke $\mathrm{J}$

$\mathrm{i}=$ input $(\mathrm{i}=1,2,3)$

$1=$ Total Biaya Opersional dan Biaya Personalia

$2=$ Total Jumlah Tenaga Pendidik dan

Kependidikan

3 = Total Jumlah Mahasiswa Aktif

Fungsi batasan pada Persamaan diatas adalah penjumlahan DMUt dibatasi sama dengan 1 . Untuk fungsi batasan kedua pada adalah batasan efisiensi DMUt yaitu penjumlahan total nilai output DMUt dengan total nilai input DMU t yang dibatasi kurang sama dengan 0. Berikut adalah persamaan linier untuk masing-masing DMU sebagai berikut : [1] Fungsi Tujuan

Fungsi Tujuan Jurusan Akuntansi

$\operatorname{Max} Z=v_{1} y_{11}+v_{2} y_{21}$
Fungsi Tujuan Jurusan Administrasi Niaga

$\operatorname{Max} Z=v_{1} y_{12}+v_{2} y_{22}$

Fungsi Tujuan Jurusan Teknik Elektronika

$\operatorname{Max} Z=v_{1} y_{13}+v_{2} y_{23}$

Fungsi Tujuan Jurusan Teknik Informasi

$\operatorname{Max} Z=v_{1} y_{14}+v_{2} y_{24}$

Fungsi Tujuan Jurusan Teknik Kimia

$\operatorname{Max} Z=v_{1} y_{15}+v_{2} y_{25}$

Fungsi Tujuan Jurusan Teknik Mesin

$\operatorname{Max} Z=v_{1} y_{16}+v_{2} y_{26}$

Fungsi Tujuan Jurusan Sipil

$\operatorname{Max} Z=v_{1} y_{17}+v_{2} y_{27}$

[2] Fungsi Batasan

Penjumlahan Input Jurusan Akuntansi

$u_{1} x_{11}+u_{2} x_{21}+u_{3} x_{31}+u_{4} x_{41}=1$

Penjumlahan Input Jurusan Administrasi Niaga

$u_{1} x_{11}+u_{2} x_{21}+u_{3} x_{31}+u_{4} x_{41}=1$

Penjumlahan Input Jurusan Teknik Elektronika

$u_{1} x_{11}+u_{2} x_{21}+u_{3} x_{31}+u_{4} x_{41}=1$

Penjumlahan Input Teknik Informasi

$u_{1} x_{11}+u_{2} x_{21}+u_{3} x_{31}+u_{4} x_{41}=1$

Penjumlahan Input Teknik Kimia

$u_{1} x_{11}+u_{2} x_{21}+u_{3} x_{31}+u_{4} x_{41}=1$

Penjumlahan Input Teknik Mesin

$u_{1} x_{11}+u_{2} x_{21}+u_{3} x_{31}+u_{4} x_{41}=1$

Penjumlahan Input Teknik Sipil

$u_{1} x_{11}+u_{2} x_{21}+u_{3} x_{31}+u_{4} x_{41}=1$

[3] Konstrain efisiensi DMU

Konstrain efisiensi DMU Jurusan Akuntansi

$u_{1} x_{11}+u_{2} x_{21}+u_{3} x_{31}+u_{4} x_{41}-v_{1} y_{11}-v_{2} y_{21} \leq 0$

Konstrain efisiensi DMU Jurusan Administrasi

Niaga

$u_{1} x_{12}+u_{2} x_{22}+u_{3} x_{32}+u_{4} x_{41}-v_{1} y_{12}-v_{2} y_{22} \leq 0$

Konstrain efisiensi DMU Jurusan Teknik Elektronika

$u_{1} x_{13}+u_{2} x_{23}+u_{3} x_{33}+u_{4} x_{41}-v_{1} y_{13}-v_{2} y_{23} \leq 0$ 
Konstrain efisiensi DMU Jurusan Teknik Informasi $u_{1} x_{14}+u_{2} x_{24}+u_{3} x_{34}+u_{4} x_{41}-v_{1} y_{14}-v_{2} y_{24} \leq 0$ Konstrain efisiensi DMU Jurusan Teknik Kimia $u_{1} x_{15}+u_{2} x_{25}+u_{3} x_{35}+u_{4} x_{41}-v_{1} y_{15}-v_{2} y_{25} \leq 0$ Konstrain efisiensi DMU Jurusan Teknik Mesin $u_{1} x_{16}+u_{2} x_{26}+u_{3} x_{36}+u_{4} x_{41}-v_{1} y_{16}-v_{2} y_{26} \leq 0$ Konstrain efisiensi DMU Jurusan Teknik Sipil $u_{1} x_{17}+u_{2} x_{27}+u_{3} x_{71}+u_{4} x_{41}-v_{1} y_{17}-v_{2} y_{2} \leq 0$ [4] Konstrain bobot input dan output $u_{1}, u_{2}, u_{3} \geq 0$ $v_{1}, v_{2} \geq 0$

Koefisien $\mathrm{y}_{11}$ diperoleh dari data output Jumlah Lulusan, koefisien y21 diperoleh dari data output Jumlah Penelitian. Begitu juga untuk data input $\mathrm{x}_{11}$ didapatkan dari data Jumlah Tenaga Pendidik dan Kependidikan, $\mathbf{x}_{21}$ didapat dari Jumlah Mahasiswa Aktif, dan $\mathrm{x}_{31}$ didapat dari Jumlah Biaya Operasional dan Biaya Personalia.

Setelah persamaan linier DEA untuk seluruh DMU selesai dibangun maka dapat dihitung nilai efisiensi teknis untuk tiap DMU.Perhitungan nilai efisiensi teknis ini dilakukan dengan menggunakan aplikasi Banxia Frontier Analys 4.DMU dikatakan efisien jika nilai objective function atau skor yang dihasilkan adalah $1(100 \%$ dalam aplikasi) dan DMU dikatakan tidak efisien atau inefisien jika nilai objective function < 1.Jika suatu DMU memiliki nilai efisiensi kurang dari 1 maka langkah berikutnya yang dilakukan adalah pemberian rekomendasi agar DMU tersebut menjadi efisien.penyajian perhitungan efisiensi teknis untuk ketujuh DMU pada tiga periode disajikan pada tabel berikut.

Tabel 4

Nilai Efisiensi Tahun 2014-2016

\begin{tabular}{|c|c|c|c|}
\hline \multirow{2}{*}{$\begin{array}{c}\text { Nama } \\
\text { Jurusan } \\
\text { (DMU) }\end{array}$} & 2014 & 2015 & 2016 \\
\cline { 2 - 4 } & 1 & 1 & 0,992 \\
\hline AK & 1 & 1 & 0,996 \\
\hline AN & 0,858 & 1 & 1 \\
\hline TE & 1 & 1 & 1 \\
\hline TI & 1 & 1 & 1 \\
\hline TK & 1 & 1 & 0,990 \\
\hline TM & 1 & 1 & 1 \\
\hline TS & 1 & & \\
\hline
\end{tabular}

Berdasarkan tabel 3, pada tahun 2014 dari 7 Jurusan terdapat 5 jurusan yang memiliki skor efisiensi sempurna atau 1 yakni jurusan AK, Jurusan TE, Jurusan TI, Jurusan TM dan Jurusan TS. Sedangkan 1 Jurusan yang tersisa tidak memiliki skor efisiensi sempurna, hal ini bisa dikatakan bahwa Jurusan yang bersangkutan tidak efisien atau inefisien karena skornya kurang dari 1 (satu). Kedua jurusan tersebut ialah Jurusan AN dengan skor 0,858 .

Pada tahun 2015 dari 7 Jurusan, seluruh Jurusan efisien karena semua Jurusan memiliki skor 1. Kondisi inilah yang diharapkan dapat dipertahankan oleh masing-masing jurusan. Kondisi ini menggambarkan bahwa seluruh jurusan pada tahun 2015 memiliki kemampuan kinerja yang baik dalam mengelola sumber daya (input) untuk menghasilkan output yang optimal.

Pada tahun 2016 dari 7 Jurusan terdapat 4 jurusan yang memiliki skor efisiensi sempurna atau 1 yakni Jurusan TE, Jurusan TI, Jurusan TK, dan Jurusan TS. Sedangkan 3 Jurusan yang tersisa tidak memiliki skor efisiensi sempurna, hal ini bisa dikatakan bahwa Jurusan yang bersangkutan tidak efisien atau inefisien. Ketiga jurusan tersebut ialah Jurusan AK dengan skor 0,992, Jurusan AN dengan skor 0,996, Jurusan kemudian yang terakhir ialah Jurusan TM dengan skor 0,990.

\section{Kesimpulan dan Saran}

Berdasarkan hasil analisis tingkat efisiensi Jurusan di Politeknik Negeri Malang menggunakan metode Data Envelopment Analysis (DEA) periode tahun 2014 sampai dengan tahun 2016, berikut kesimpuan dari penelitian ini :

1. Pada tahun 2014 terdapat 6 jurusan yang efisien ( mencapai skor 1) yakni jurusan Akuntansi, Jurusan Teknik Elektronika, Jurusan Teknik Informasi, Jurusan Teknik Mesin, Jurusan Teknik Kimia dan Jurusan Teknik Sipil.

2. Pada tahun 2015, seluruh Jurusan dalam kondisi efisien.

3. Pada tahun 2016 terdapat 4 Jurusan yang efisien ( mencapai skor 1) yakni Jurusan Teknik Informasi, Teknik Kimia dan Teknik Sipil.

\section{Saran}

Saran untuk penelitian selanjutnya ialah diharapkan dapat meneliti dengan menggunakan metode yang berbeda yakni menggunakan BCC, dan input atau pun output yang berbeda.

\section{Daftar Pustaka}

Abbott, M., \& Doucouliagos, C. (2003). The Efficiency of Australian University : A Data Envelopment Analysis. 23, 89-97.

Abidin dan Endri. (2009). Kinerja Efisiensi Teknis Bank Pembangunan Derah : Pendekatan Data Envelopment Analysis (DEA). Jurnal Akuntansi dan Keuangan, Vol. 11 No 1, 21-29.

Arta et al. (2014). Analisis Efisiensi Alokatif FaktorFaktor Produksi Sorgum di Kabupaten Gunung Kidul. Agro Ekonomi Vol 24/No.

Chiang, K., \& Hsi, TH. (2006). Efficiency Analysis of University Departments: An Empirical Study. 36, 653-664.

Cooper, W.W., Seiford, L.M., \& Tone, K. (1999). Data Envelopment Analysis; A Comprehensive Text with Models, Applications, References 
and DEA-Solver Software. South America. Kluwer Academica Publisher.

Filardo et al. (2017). Penerapan Data Envelopment Analysis dalam Pengukuran Efisiensi Retailer Produk Kendaraan Merek Toyota.Jurnal Sains dan Seni ITS vol 6 no 1.

Geraint, J., \& Manuel S. (2007). The Determinants of Costs and Efficiencies Where Producers Are Heterogeneous: Vol.4.no 15. 1-9.

Handaru, j. (2015). Penilaian Efisiensi Universitas di LPTK Indonesia dengan Menggunakan Data Envelopment Analysis. Universitas Negeri Yogyakarta: ELINVO.

Jill, J., \& Geraint, J. (1995). Reaserch Funding and Performance in U.K. University Departments of Economics: A Frontier Analysis. Department of Economics, The Management School, Lancaster University, Lancaster LA 4 YX, UK.

KBBI.(2017) Arti Efisiensi. Diakses pada tanggal 9 April 2018. Dari https://www.kbbi.web.id/efisiensi.

Mulyadi.(2008), Akuntansi Biaya, Edisi Lima, Yogyakarta, Aditya Media.

M. J. Farrell. (1957)Measurement of Productive Efficiency.Journal od the Royal Statixtical Society. Series A (General), vol 120. No 3.

Eltivia, N., Setiawan, M.A., \& Ernawati, W.D (2015). Study Program's Evaluation Using Data Envelopment Analysis. International Journal Economic Policy in Emerging Economics. Voll 11 No, 1/2, page 133-140.

Reka, T. (2007). Using DEA to Evaluate Efficiency of Higher Education. University Of Debercen: APSTRACT.

Al-Bagoury.(2013). DEA To Evaluate Efficiency of African Higher Education. Cairo University: African Institute of Research and Studies.

Sugiyono. (2013). Statistika untuk Penelitian.Bandung : Alfabeta. 